\title{
DISTOPÍAS CLIMÁTICAS EN EL CINE CONTEMPORÁNEO: ECOFEMINISMO PARA SALVAR EL MUNDO EN MAD MAX: FURIA EN LA CARRETERA
}

\author{
Marta Marín Gavilá \\ Universitat de València
}

\begin{abstract}
Resumen: Vivimos actualmente en un mundo cada día más contaminado y parece que nos precipitamos al abismo casi sin darnos cuenta. El cine, a lo largo de la historia, ha imaginado posibles escenarios de lo que supondría todo ello, atendiendo a nuestras preocupaciones y miedos más reales, alertándonos de las posibles consecuencias de un apocalipsis que parece casi inminente. Mad Max: Furia en la carretera (George Miller, 2015), no solo nos ofrece un ejemplo renovado de este tipo de cine, sino una solución real al problema actual que nos afecta.
\end{abstract}

Palabras clave: mundos distópicos, clima ficción, ecofeminismo, Mad Max.

Climatic dystopias in contemporary cinema: Ecofeminism to save the world in Mad Max: Fury Road

Abstract: We currently live in a world that is becoming more polluted every day and it seems that we are plunging into the abyss almost without realizing it. The cinema, throughout history, has imagined possible scenarios of what that would mean, attending to our most real concerns and fears, alerting us of the possible consequences of an apocalypse that seems almost imminent. Mad Max: Fury Road (George Miller, 2015), not only offers us a renewed example of this type of cinema, but a real solution to the current problem that is affecting us.

Key words: dystopian worlds, climate fiction, ecofeminism, Mad Max.

\section{INTRODUCCIÓN}

A comienzos del año 2018 el Doomsday Clock, conocido popularmente como "reloj del apocalipsis", creado en 1947 por el Boletín de Científicos Atómicos de la Universidad de Chicago, fue adelantado a las 23:58, es decir, a tan sólo dos minutos del fin del mundo. Este reloj puramente simbólico, mide en cuestión de minutos y horas el grado de amenaza medioambiental, nuclear o tecnológica que puede poner fin a la humanidad, y llegar a la medianoche, es decir a las 00:00, supondría la destrucción total. Debido a la creciente proble-

Data de recepció: 20 de maig de 2019 / Data d'acceptació: 3 d'octubre de 2019. 
mática medioambiental, pero sobre todo a las tensiones nucleares entre Corea del Norte y Estados Unidos, nos encontramos, en la actualidad, en el momento más peligroso que ha vivido la humanidad desde la Guerra Fría, en concreto desde 1953, momento en el que Estados Unidos desarrolló la bomba de hidrógeno. El propio Stephen Hawking, reputado físico teórico, afirmó: "Este es el momento más peligroso para nuestro planeta" (Hawking, 2016), y otros académicos y expertos que estudian los riesgos existenciales, advierten que el cambio climático y la guerra nuclear serán las mayores amenazas que afrontar a mediados de este siglo (Salas, 2017).

En un mundo cada día más contaminado y con fenómenos atmosféricos extremos cada vez más frecuentes, todas estas evidencias deberían estremecernos, sin embargo, no somos realmente conscientes del peligro que supone todo ello. Partiendo de este contexto tan desalentador y alarmante, estableceremos una mirada crítica a nuestro presente, a través de toda una serie de ficciones audiovisuales contemporáneas que han tratado estos temas mediante la recreación de escenarios distópicos y poco esperanzadores. Con esta investigación, resaltaremos por tanto, la importancia de este tipo de producciones a la hora de visibilizar toda esta problemática mundial, situando el foco de atención en cómo el cine actual imagina el destino de la humanidad, en cómo todas esas catástrofes medioambientales calan en nuestro imaginario, y en cómo se hace uso de toda esta crisis ecológica y nuclear para crear sin duda, un paralelismo entre realidad y ficción.

Tras estudiar y establecer una mirada crítica sobre algunos de los filmes actuales más característicos, nos centraremos en el análisis de la última e innovadora cinta del director australiano George Miller, Mad Max: Furia en la carretera y en las soluciones que nos plantea dicha película, para tratar de ofrecer un ejemplo renovado en cuanto a cine comercial y de clima ficción, pues esta cinta se nos presenta aquí como un filme ecofeminista, y por lo tanto como una singularidad dentro de la industria hollywoodense actual. Para constatar todo ello, el presente artículo seguirá una serie de enfoques metodológicos, como el análisis fílmico de Mad Max: Furia en la carretera y su lectura iconológica y semiótica, es decir, la lectura de su significado, su puesta en valor, la importancia y la profundidad del mensaje y de su trasfondo, en este caso, su interpretación ecofeminista, que se va a justificar a través del estudio de las fuentes escritas sobre esta corriente del feminismo y de la ecología. Todo ello nos llevará a tratar temas relacionados con la ecología, el feminismo, la política, el medio ambiente, la religión y el fin del mundo. 


\section{CLIMA FICCIÓN}

A lo largo de la historia, el cine ha servido como catalizador de los miedos, las preocupaciones y las inquietudes sociales, especialmente cuando nos referimos al fin del mundo o al apocalipsis. En este sentido, el llamado género cli-fi o clima ficción, el cual podríamos considerar como un subgénero de la ciencia ficción, ha tratado ampliamente estas problemáticas tanto en el cine como en la literatura, y suele recrear, ya sea en un presente o en un futuro ficticio, contextos distópicos vinculados con los efectos del cambio climático, el calentamiento global, la contaminación, la explotación de los recursos naturales, o desastres nucleares que afecten al medioambiente y al ecosistema.

Una de las obras clave de la literatura de clima ficción es Un mundo sumergido (1962) de J.G. Ballard, en la que se recrea un futuro planeta Tierra totalmente sepultado bajo el agua debido al deshielo de los casquetes polares. A esta obra le seguirían otras del mismo autor como: El huracán cósmico (1963), La Sequía (1964) y El mundo de cristal (1966), toda una saga apocalíptica en la que el clima es el principal enemigo y que sin duda tendrían una gran influencia en el mundo literario y audiovisual.

Pero ya en los años treinta, encontramos películas como la francesa La fin du monde (Abel Gance, 1931), en la que se recrea el posible comportamiento humano ante la inminente colisión de un cometa contra la Tierra, o la estadounidense Deluge (Felix E. Feist, 1933), donde un eclipse solar provoca una ola gigante que arrasa ciudades. Aunque estas cintas, más que imaginar posibles apocalipsis reales, fueron, ante todo, respuestas metafóricas a la crisis económica y política de la época. Las inundaciones y las plagas no eran sino, el reflejo de la agitación de la sociedad contemporánea, una forma de abordar las ansiedades generadas por la Gran Depresión de aquellos años.

Si fijamos la vista en el cine más reciente, desde finales del siglo XX hasta nuestros días, podemos nombrar una larga lista de películas que han tratado el tema apocalíptico y post-apocalíptico o una futura destrucción o decadencia del mundo debido a la explotación de recursos o al cambio climático, y que por tanto, recrean una distopía climática o ecológica. Películas tales como las pertenecientes a la saga post-apocalíptica de Mad Max (George Miller, 1979, 1981, 1985 y 2015), Waterworld (Kevin Reynolds, 1995), El día de mañana (The Day After Tomorrow, Roland Emmerich, 2004), Hijos de los hombres (Children of Men, Alfonso Cuarón, 2006), El incidente (The Happening, M. Night Shyamalan, 2008), 2012 (Roland Emmerich, 2009), La carretera (The Road, John Hillcoat, 2009), Hell (Tim Fehlbaum, 2011), Take Shelter (Jeff Nichols, 2011), Rompenieves (Snowpiercer, Bong Joon-ho, 2013) e Interstellar 
(Christopher Nolan, 2014) son ejemplos recientes de ello. Incluso películas de animación como Nausicaä del Valle del Viento (Kaze no Tani no Naushika, Hayao Miyazaki, 1984) y Wall·E (Andrew Stanton, 2008) siguen esta línea de ficción climática y ecológica.

En el caso de quizás las dos superproducciones de catástrofes medioambientales más populares, El día de mañana y 2012, dirigidas ambas por Roland Emerich, están ubicadas en un hipotético presente y basan sus acontecimientos esencialmente en el problema del calentamiento global y el consecuente deshielo de los polos y aumento del nivel del mar. Por otro lado, también recreando un posible escenario actual, en El incidente, la mayor amenaza para el ecosistema es el propio ser humano, y las plantas comienzan a expulsar una toxina que se transmite por el aire y que hace que las personas se suiciden; a modo de autodefensa, las plantas lanzan una advertencia muy explícita del daño que está causando la humanidad al medioambiente. Tenemos otras distopías que miran en este caso hacia el futuro, como el caso de Snowpiercer, traducida al castellano como Rompenieves. En esta coproducción surcoreana y estadounidense, la Tierra vive una especie de era glacial en la que los únicos supervivientes viajan en un tren divido por clases, y donde las desigualdades sociales y los excesos del sistema capitalista se muestran y se critican de forma contundente. Estrenada en 2014, Interstellar, una cinta de ciencia ficción que bebe de películas como 2001: Una Odisea del espacio (2001: A Space Odyssey, Stanley Kubrick, 1968) para hacernos reflexionar acerca del destino de la humanidad, nos sitúa en un planeta moribundo, incapaz de generar cultivos y cosechas, donde la comida escasea y abundan las tormentas de arena. Como solución al problema medioambiental se nos propone buscar otro planeta habitable y abandonar el nuestro: "Nacemos en la Tierra, pero nuestro destino no es morir en ella" reza uno de los carteles promocionales del filme, muy en la línea de las declaraciones del físico teórico Stephen Hawking cuando afirmó en una de sus conferencias: "Es el momento de explorar otros sistemas solares. Expandirnos puede ser lo único que nos salve de nosotros mismos. Estoy convencido de que los humanos necesitan irse de la Tierra" (Hawking, 2017).

El cine más independiente, también ha dado cuenta de todos estos temores o ha imaginado posibles escenarios de lo que nos espera. Take Shelter, relata la historia de un padre de familia que comienza a tener premoniciones de un apocalipsis inminente, la película se debate entre si son realmente premoniciones o alucinaciones causadas por una enfermedad mental. Podría aludir a la despreocupación generalizada que existe en la sociedad actual acerca de estos problemas, llegando a tildar de locos a aquellos que avecinan el fin del mundo, cuando en realidad, como se descubre al final de la película, tienen razón. Otros filmes, como La carretera o la alemana Hell, se centran en la evolución de una 
pareja de personajes en un contexto post-apocalíptico, donde sobrevivir en un páramo hostil repleto de peligros será el principal objetivo.

Cabe destacar además, películas de animación post-apocalípticas y con evidentes mensajes ecologistas, como Nausicaä del Valle del Viento, anime de 1984 donde se nos plantea la necesidad de preservar y cuidar la naturaleza para el bienestar de la humanidad, criticando de forma contundente la guerra, no sólo como amenaza para nuestra supervivencia, sino también para la conservación del planeta. Por otro lado, en la conocida producción de Disney y Pixar, Wall $\cdot E$, la Tierra ha sido abandonada por el ser humano y se encuentra cubierta por toda una capa de basura; la misión de los robots protagonistas, será la de rescatar el último vestigio de naturaleza que queda en ella.

De lo que no cabe duda es que, el hecho de que un medio como el cine reflexione o haga reflexionar al público acerca de estos temas, supone sin duda una herramienta fundamental a la hora de alertar y concienciar a la población. Por ejemplo, un blockbuster hollywoodense, fabricado y pensado para ser consumido por un público de masas, es capaz de llegar a muchas más personas de lo que se podría esperar de cualquier texto científico o incluso de un documental acerca del cambio climático. Pero ¿quiénes son los protagonistas de estas historias? ¿Qué soluciones nos muestra el cine ante un posible apocalipsis? ¿Sirven estos ejemplos para concienciar a los espectadores sobre el calentamiento global?

Según Julia Leyda, del Instituto de Estudios Avanzados de Sostenibilidad de Potsdam (Alemania), en un artículo publicado en un recopilatorio de un workshop denominado The Dystopian Impulse of Contemporary Cli-Fi, la gran mayoría de películas mainstream que tocan estos temas tienden a apelar al denominador común en sus audiencias, y por lo tanto no se puede esperar que ofrezcan representaciones políticamente innovadoras. Según Leyda, estos filmes son la forma más común del término "liberal" en algunas áreas, mientras que al mismo tiempo optan por convenciones más conservadoras o convencionales en otras. Por ejemplo, un gran número de películas $c l i-f i$ centran su desarrollo alrededor de figuras heroicas paternas que intentan rescatar no sólo a sus familias, sino al mundo del desastre, reforzando los valores patriarcales tradicionales (Leyda, 2016, 14). Además de ello, destaca que el machismo exhibido en la valentía de sus actos físicos, es rebajado por sus lealtades con esas causas "liberales" tales como la ecología o el ambientalismo, su devoción por su familia o su humanidad. Motivos paternos similares son los que animan, por ejemplo, al protagonista de Take Shelter, un hombre alto y robusto, cuya extrema protección de su esposa y su frágil hija se alimenta de lo que parece ser una forma de enfermedad mental en la que prevé una catastrófica tormenta que amenaza a toda la ciudad. Sin embargo Leyda identifica la película alemana Hell como una rara excepción (Leyda, 2016, 14), en la que dos hermanas 
luchan por sobrevivir en un mundo post-apocalíptico creando alianzas con personajes masculinos, sin duda, y como constataremos más adelante, muy en la línea de Mad Max: Furia en la carretera.

De hecho, y reafirmándonos en los estudios de Leyda, si nos fijamos en las películas nombradas anteriormente, exceptuando un par de ellas, todas están protagonizadas por hombres sobre los cuales recae la misión de salvar tanto a su familia como a la humanidad o lo que queda de ella. Por lo tanto, la pregunta que deberíamos plantearnos es ¿dónde quedan los personajes femeninos en este tipo de películas? ¿Cuál es el papel de la mujer en el fin del mundo? La mayoría de ficciones audiovisuales distópicas que llegan a nuestras pantallas, nos muestran a las mujeres en papeles que casi siempre responden al de víctimas que necesitan que las rescaten o de acompañantes del héroe masculino en cuestión, por no hablar de la cosificación y sexualización a la que se ven sometidas muchas de ellas o la diferencia de edades entre actores y actrices. Es por ello que cuando un filme rompe todos estos esquemas, podemos comenzar a hablar de concienciación social en todos los sentidos, y Mad Max: Furia en la carretera va a ser ejemplo de ello.

\section{APROXIMACIÓN A MAD MAX: FURIA EN LA CARRETERA}

Estrenada en el año 2015, Furia en la carretera retoma al personaje de la saga post-apocalíptica que George Miller creó a finales de los años setenta, Max Rockatansky, un ex policía atormentado por su turbulento pasado y que lo ha perdido todo excepto su instinto de supervivencia. Miller lo sitúa en una historia sin conexión alguna con las películas de la trilogía original, excepto por su protagonista masculino y por su contexto de mundo post-apocalíptico, coches y ultraviolencia. Aún así, el personaje de Max, interpretado en las tres primeras cintas de la saga por Mel Gibson, cambia de imagen y el papel recae esta vez en el actor inglés Tom Hardy.

La historia de Furia en la carretera se ubica, al igual que el resto de películas de la franquicia, en un mundo post-apocalíptico devastado por un conflicto termonuclear, donde recursos como el agua y la gasolina generan guerras y desesperación entre la población, y donde la tierra ácida y el clima árido y desértico imposibilitan el cultivo de cualquier tipo de vegetación. Una arriesgada misión de huída y una persecución continua, es lo que guiará toda la trama de la película. Charlize Theron en el papel de Imperator Furiosa, arranca la persecución principal dirigiendo su enorme "máquina de guerra nitro-propulsada de dos mil caballos" y desviándola del recorrido habitual durante una visita rutinaria de abastecimiento a la Ciudad de la Gasolina. Aparte de transportar depósitos de 
agua y leche materna para supuestamente intercambiarlos por gasolina, Imperator Furiosa esconde una carga secreta dentro de su camión de guerra: las cinco Esposas reproductoras de Immortan Joe que quieren huir del malvado tirano para encontrar el Paraje Verde, donde Furiosa nació, y donde según ella, serán libres y podrán vivir de los recursos de la tierra. Immortan Joe, caudillo de La Ciudadela y dueño absoluto del suministro de agua a la que llama "Aqua-Cola", pronto se da cuenta de que sus preciadas "reproductoras" han escapado con $\mathrm{Fu}$ riosa en el camión de guerra, y llama a todo su ejército de hombres "Media Vida" para recuperar sus pertenencias, es entonces cuando se inicia la persecución a través del páramo que ocupa toda la trama del filme.

En un principio, ajeno a todo ello se encuentra Max, al cual vemos como en la escena inicial de la película es capturado y amordazado por un grupo de soldados Media Vida de La Ciudadela y utilizado como una bolsa de sangre, de forma literal, para revitalizar a uno de los soldados, Nux. Cuando Immortan Joe llama a sus guerreros a la batalla, el soldado Nux se ve obligado a amarrar su "bolsa de sangre" a la parte delantera de su coche para ir suministrándose la sangre mientras conduce tras las huellas de Furiosa. Tras una tormenta de arena monumental, Max y Nux se distancian del convoy de Immortan Joe, y es cuando se ven involucrados en la misión de huída de las mujeres, a las cuales finalmente se unirán y ayudarán para poder sobrevivir en ese desierto.

Esta es la historia que nos plantea Miller treinta años después, en una película que más que una secuela o precuela de la saga Mad Max, se acerca más a una revisión de la franquicia que pretende inducir al espectador moderno a reflexionar acerca de temas trascendentales y problemáticos vinculados con la realidad, a la vez que disfruta de un espectáculo visual repleto de acción. De hecho, al contrario de lo que se podría presagiar en un principio, lo realmente interesante de esta cinta distópica es que ecología y feminismo se unen para mostrarnos cómo una civilización post-capitalista y post-patriarcal, basada en la explotación de las mujeres y de los recursos naturales, domina un panorama post-apocalíptico, en el que las únicas capaces de salvar lo que queda de humanidad y de naturaleza serán las heroínas sublevadas, encabezadas por la indiscutible protagonista de la película, Imperator Furiosa. Estaríamos por tanto ante una distopía no sólo ecologista, sino además ecofeminista por el hecho de relacionar y vincular de forma directa la dominación de la mujer con la explotación de la naturaleza.

Es importante destacar, que el filme fue estrenado el 14 de mayo de 2015 fuera de concurso en la Sección Oficial de largometrajes del Festival de Cannes de aquel año, y tal fue su impacto, que de hecho, Furia en la carretera optó a diez estatuillas en los Oscar del año 2015, incluyendo mejor película y mejor director, siendo la máxima ganadora de aquel año con seis Oscar (mejor diseño de vestuario, mejor maquillaje y peinado, mejor montaje, mejor diseño de produc- 
ción, mejor mezcla de sonido y mejor edición de sonido). Además de su sorprendente éxito en la ceremonia de premios más importante de la cinematografía, destacan sus nueve galardones por parte de los Premios de la Crítica Cinematográfica o Critics Choice Awards, entre los que le fueron concedidos el de mejor película de acción y mejor director. A Miller le otorgaron también el Gran Premio de la Federación Internacional de Críticos de Cine (FIPRESCI) a la mejor película del año (Fipresci, 2015). Aparte de estos importantes reconocimientos también estuvo nominada a mejor película de drama y a mejor director en los Globos de Oro, y todo ello después de haber sido incluida entre las diez mejores películas del año 2015 por el American Film Institute (AFI) y por la revista francesa Cahiers du Cinema, entre otras muchas más nominaciones y premios.

\section{ECOFEMINISMO PARA SALVAR EL MUNDO}

El ecofeminismo presente en el trasfondo del filme, y que veníamos advirtiendo anteriormente, ha sido reafirmado en varios ensayos o artículos que así lo defienden, como "Un nouveau printemps pour l'écoféminisme ?" escrito por Jeanne Burgart Goutal para la revista francesa Multitudes donde afirma que en películas como Mad Max: Furia en la carretera, se exalta la asociación de la mujer y la naturaleza como un remedio para una civilización contemporánea enferma de los excesos del capitalismo y de un sistema tecnocientífico (Burgart Goutal, 2017, 20). Y es que, lo que defiende el ecofeminismo en términos generales, es la existencia de un vínculo entre la dominación de la mujer y de la naturaleza por parte de una sociedad patriarcal y capitalista. Esta sociedad, vendría a estar encarnada en el filme por el antagonista principal, Immortan Joe, el cual, ejerce un dominio y explotación de los recursos naturales, a la vez que controla los cuerpos de las mujeres para su propio beneficio, en su caso, las Esposas reproductoras y las denominadas Madres de la Leche, las cuales existen en esta sociedad ficticia para producir leche materna, es decir, son ordeñadas de forma literal.

Esta posición política, es visualizada en la película sobre todo a través de las frases: "Nuestros hijos no serán caudillos" (Fig. 1), "No somos cosas" (Fig. 2) y “¿Quién se ha cargado el mundo?” (Fig. 3), las cuales aparecen escritas a modo de protesta en los muros y en el suelo de la celda donde el villano tiene recluidas a sus Esposas. Frases que aluden sin duda a la liberación de las mujeres y al fin del mundo. “¿Quién se ha cargado el mundo?” es una pregunta que se repite a lo largo del filme y que tiene una respuesta sencilla: el patriarcado y su masculinidad tóxica, basada en la explotación, control y despojo de las mujeres y de los recursos del planeta Tierra. 


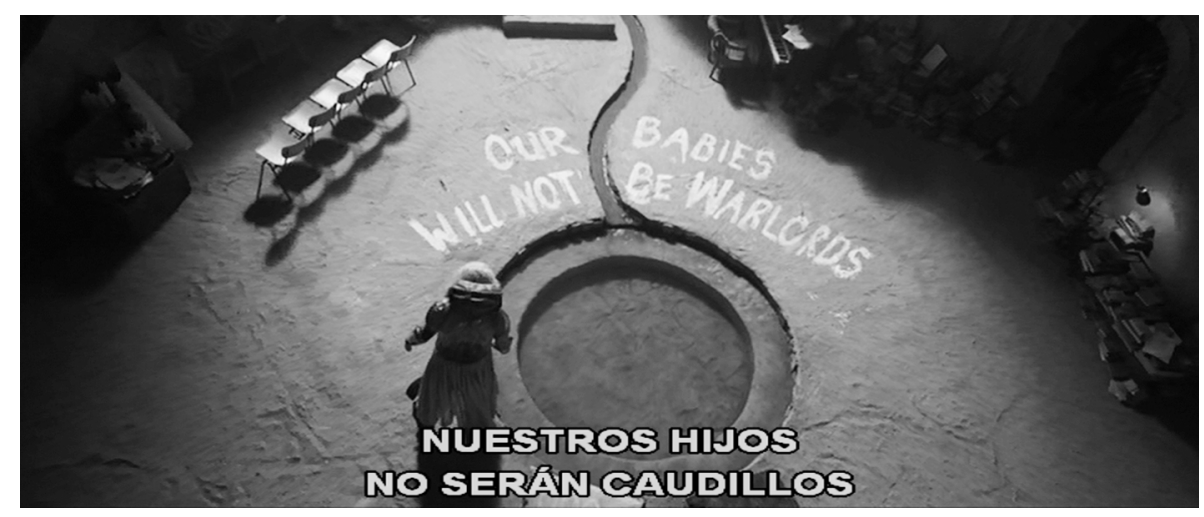

Fig. 1. Fotograma de Mad Max: Furia en la carretera (Mad Max: Fury Road, George Miller, 2015). Interior de la celda de las Esposas. Captura de pantalla.

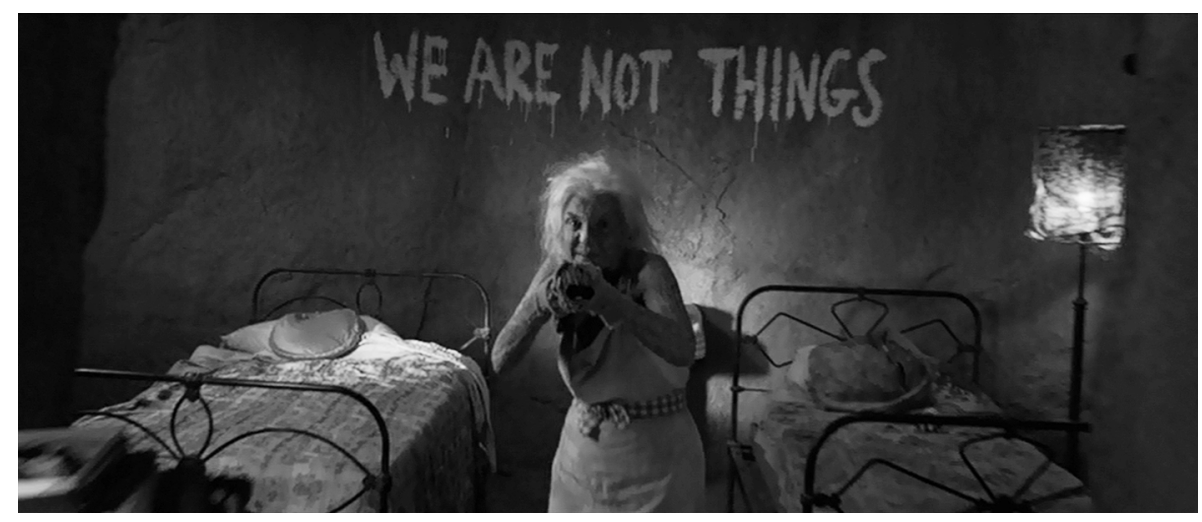

Fig. 2. Fotograma de Mad Max: Furia en la carretera (Mad Max: Fury Road, George Miller, 2015). Interior de la celda de las Esposas. Destaca la pintada de la pared en la que puede leerse "No somos cosas". Captura de pantalla. 


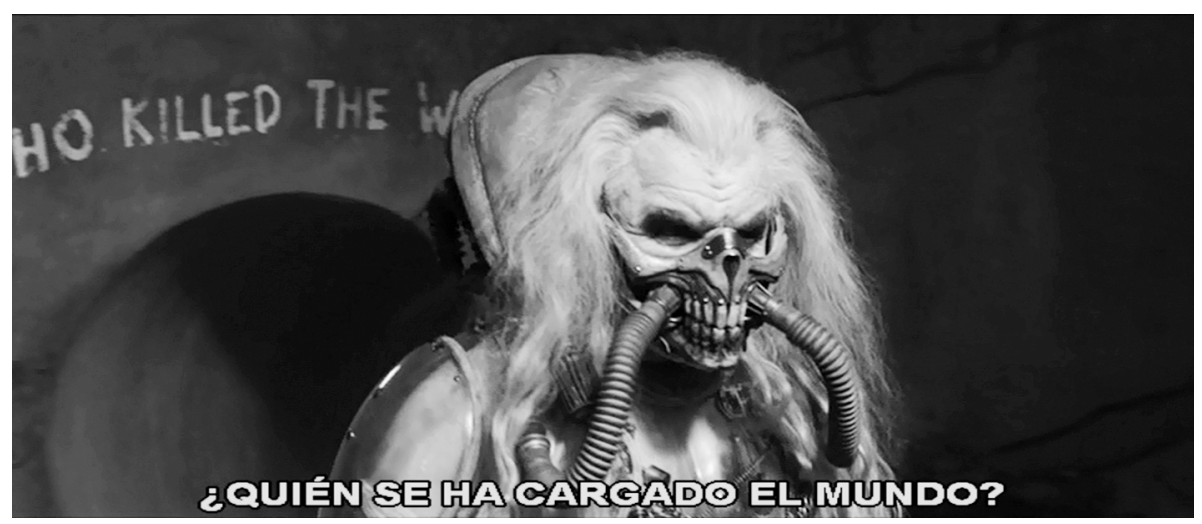

Fig. 3. Fotograma de Mad Max: Furia en la carretera (Mad Max: Fury Road, George Miller, 2015). Interior de la celda de las Esposas. Destaca la pintada en la pared. Captura de pantalla.

De hecho, basándonos en las teorías ecofeministas, encontramos una gran cantidad de semejanzas entre esta rama del feminismo y de la ecología y la última cinta de Miller. Como bien afirma Alicia H. Puleo, se dice que hay tantos ecofeminismos como teóricas ecofeministas (Puleo, 2011, 29), veamos pues las distintas propuestas de este movimiento y su plasmación en el filme centrando la atención en los primeros planteamientos de Françoise d'Eaubonne, en el ecofeminismo clásico o radical y el ecofeminismo de la Teología de la Liberación que propone Rosemary Radford Ruether.

El ecofeminismo como tal, como teoría, aparece a mediados de los años setenta en Francia, debido a la influencia de la preocupación ecologista en torno al problema de la sobrepoblación. Françoise d'Eaubonne (París, 19202005), feminista libertaria, acuñó el término "ecofeminismo", creando ese punto de encuentro entre feminismo y ecologismo. Afirmaba que si las mujeres hubieran tenido el poder, históricamente hablando, habrían espaciado los embarazos y no se hubiera llegado a esa situación de superpoblación. Defiende por tanto la liberación de las mujeres como liberación de su sexualidad, y sostiene que la conquista del control de sus propios cuerpos sería el comienzo de un camino no consumista, ecologista y feminista. Esto último concuerda con el propósito de las protagonistas de Furia en la carretera, las cuales reclaman la libertad de sus cuerpos como punto de partida para conseguir un mundo mejor, y es que en efecto, el control sobre las mujeres, su reproducción y su lactancia, se vuelven fundamentales en esa distopía que recrea el filme. El cuerpo de la mujer y su capacidad reproductiva, no sólo son motivo de representación, sino que además están en el centro mismo de la narrativa. 
La teórica francesa plantea además una hipótesis sobre el pasado de la humanidad, la hipótesis de un matriarcado originario. En los albores de nuestra especie no estaba clara la conexión entre la unión sexual y la gestación, y el descubrimiento de la función paterna en la procreación habría destronado a la mujer en el imaginario prehistórico, convirtiéndola en simple terreno que se puede poseer y fecundar, se trataría pues de un simple objeto de apropiación. Fertilidad y fecundidad se habrían convertido así en capacidades manejadas por los hombres (Puleo, 2011, 35-36). En el caso de Furia en la carretera, todo ello se refleja en la figura del villano, Immortan Joe, el cual, como decíamos anteriormente, controla la fertilidad de sus "reproductoras" con el propósito de mantener vivo su linaje masculino. Françoise d'Eaubonne defiende también la existencia de sociedades occidentales organizadas en clanes de carácter agrícola y pacífico anteriores al desarrollo de un patriarcado guerrero (Puleo, 2011, 36). El paralelismo con el filme lo encontramos en las Muchas Madres del Paraje Verde, ahora constituidas únicamente por las Vuvalini, una tribu nómada de mujeres motoristas y guerreras que ayudarán a Furiosa y a las Esposas en su misión, y las cuales protegen los últimos vestigios de la naturaleza destruida por ese patriarcado guerrero, las semillas. En su opinión, estos clanes ponían a la mujer en el centro de su organización social equitativa entre los sexos. El posterior desequilibrio de poder entre hombres y mujeres habría conducido a la crisis ecológica actual, en el caso del filme, la devastación del mundo debido a un conflicto termonuclear. Al convertirse en amo absoluto de la fertilidad de los cuerpos y de la tierra de cultivo, el hombre habría iniciado una carrera expansiva desmedida que terminaría en la superpoblación, la contaminación y el agotamiento de los recursos, según afirma la ecofeminista (Puleo, 2011, 36). Estas últimas líneas definen perfectamente a Immortan Joe y las consecuencias de su gobierno, pues tanto el caudillo como sus seguidores están visiblemente enfermos o malformados debido a la contaminación de la tierra, del aire y de la sangre. Además el agua escasea entre la población, ya que Immortan Joe es su dueño absoluto y la denomina "Aqua-Cola", una clara referencia al consumo capitalista impuesto por las grandes multinacionales que incluso genera adicción. "No os volváis, amigos, adictos al agua. Podrá con vosotros y sufriréis su ausencia." dictamina el tirano. Este consejo sobre el excesivo amor por el agua podría traducirse fácilmente, según Keith Clavin en su artículo Living, Again: Population and Paradox in Recent Cinema, en declaraciones sobre combustibles fósiles, automóviles u otras adicciones al consumo en Occidente (Clavin, 2016, 59). Se podría decir por consiguiente, que Immortan Joe es la

\footnotetext{
1 Alude a la marca de refrescos Coca-Cola.
} 


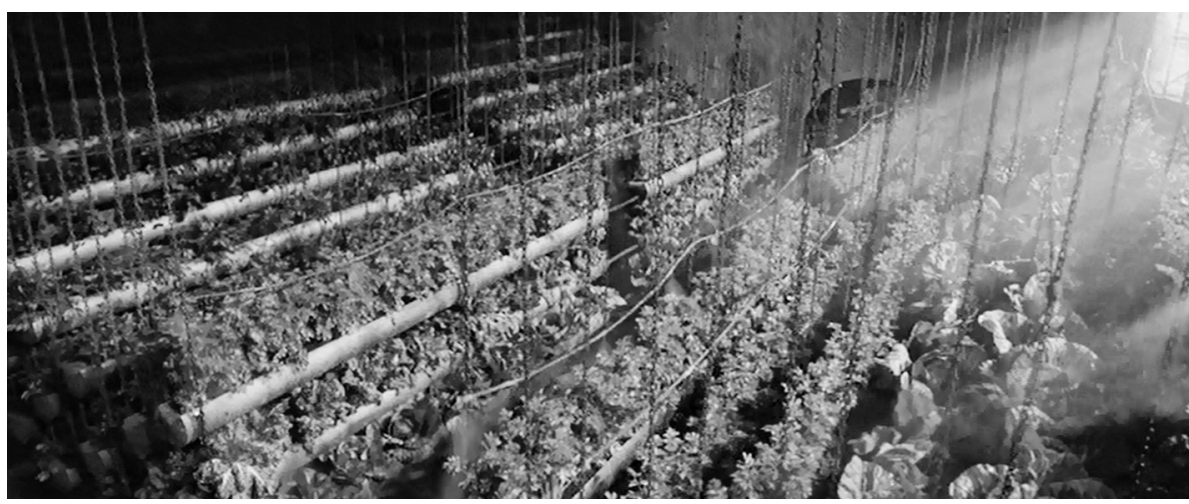

Fig. 4. Fotograma de Mad Max: Furia en la carretera (Mad Max: Fury Road, George Miller, 2015). Parte de la vegetación que acapara Immortan Joe. Captura de pantalla.

viva imagen del capitalismo global actual, pues acapara toda la vegetación que siembra (Fig. 4), domina a las masas mediante el control del agua (Fig. 5), promueve el comercio con otras ciudades para poder ejercer la violencia (importa balas y gasolina a cambio de agua y leche materna), respalda el cuidado y la salud de las mujeres y los niños siempre y cuando estos sirvan a sus intereses reproductivos, y atiende el aspecto educativo y religioso de los ciudadanos para así poder dominarlos.

Hacia finales de los años setenta, y ya en los ochenta, algunas corrientes del feminismo radical recuperaron la antigua identificación patriarcal de mujer y naturaleza para darle un nuevo significado. Invirtieron la valoración de este par conceptual que en los pensadores tradicionales servía para justificar la inferioridad de la mujer, así por ejemplo, en Hegel, la mujer es presentada como más próxima a formas de vida consideradas inferiores al hombre (animales y vegetales). Estas feministas radicales afirmaban que la cultura masculina, obsesionada por el poder, nos ha conducido a guerras suicidas y al envenenamiento de la tierra, el agua y el aire, que es todo lo que se nos presenta en ese mundo postapocalíptico de Mad Max. La mujer, más próxima a la naturaleza, es la esperanza de conservación de la vida. La ética femenina del cuidado y de la protección de los seres vivos se opone así, a la esencia agresiva de la masculinidad generada por la cultura patriarcal. Vemos pues en el clan de las Vuvalini, esa identificación de la mujer con la naturaleza y de conservación de la vida, en su caso las semillas, las cuales conservan como su bien más preciado, en contraste con la violencia y agresividad de la sociedad patriarcal representada en el filme. 


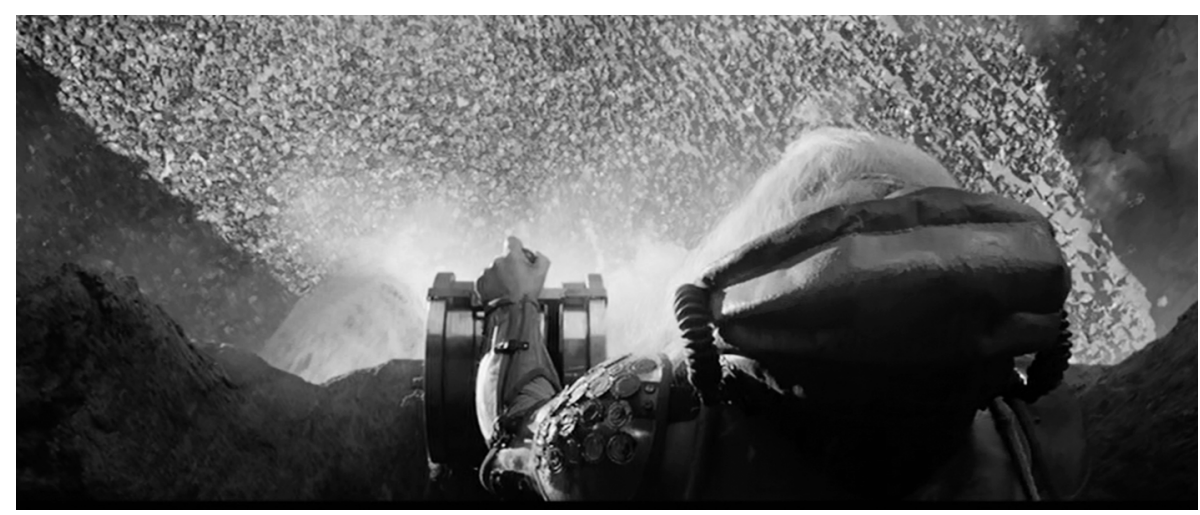

Fig. 5. Fotograma de Mad Max: Furia en la carretera (Mad Max: Fury Road, George Miller, 2015). Immortan Joe controlando a las masas mediante el suministro de agua potable. Captura de pantalla.

Este ecofeminismo, llamado hoy en día clásico, radical o biologicista, es claramente un feminismo de la diferencia que afirma que hombres y mujeres constituyen esencias opuestas, es decir, las mujeres se caracterizarían por un erotismo no agresivo e igualitarista y por aptitudes maternales que las predispondrían al pacifismo y a la preservación de la naturaleza. En cambio, los varones se verían naturalmente abocados a empresas competitivas y destructivas. Este dualismo ginocéntrico suscitó fuertes críticas dentro del feminismo, pues lo acusaban de demonizar al varón. Pero es justamente en esta rama del ecofeminismo, donde más se ven reflejados los personajes de la cinta de Miller.

Una de las teóricas referentes de esta corriente es Mary Daly (EE.UU., 1928-2010). En su obra Gyn/Ecology, afirma que la única religión existente es el culto al patriarcado y que la naturaleza masculina tendría, según la autora, una tendencia innata a la agresividad que daría como resultado una civilización basada en la guerra (Puleo, 2011, 49), una civilización retratada de forma extrema en Furia en la carretera. Argumenta también que la pasión viril por la técnica sería necrofilia y ansia de dominación que se expresa en el "fenómeno Frankenstein", que es la obsesión por ir más allá de los límites de la naturaleza y crear cyborgs. La industria armamentística es analizada por tanto como un fenómeno de compensación por la incapacidad del varón de dar a luz (Puleo, 2011, 49). Si analizamos esto último y lo relacionamos con la necropolítica recreada en la película y de la que habla Taylor Boulwaire en su artículo 'Who killed the world?': Building a Feminist Utopia from the Ashes of Toxic Masculinity in Mad Max: Fury Road (2016, 1-17), basándose en las teorías del 
teórico político y filósofo Achille Mbembe, todo cobra sentido. Esencialmente, la necropolítica es una forma extrema de poder en la que el despliegue de la fuerza, la subyugación y el control social está motivado no por la necesidad de organizar temas para la vida, sino para la muerte. Más bien, una soberanía necropolítica es aquella en la que según Mbembe:

se despliegan armas en aras de la destrucción máxima de las personas y la creación de mundos mortales, formas nuevas y únicas de existencia social en las que vastas poblaciones están sometidas a condiciones de vida que les confieren el estatus de muertos vivientes (Boulwaire, 2016, 7).

En su discusión sobre esos "muertos vivientes", Mbembe hace referencia a la esclavitud de los Estados Unidos, al Holocausto, al apartheid sudafricano y a la ocupación actual de Palestina, pues esta forma de soberanía no organiza a la sociedad para el mantenimiento de la vida a fin de mantener el capitalismo, sino que maximiza la muerte de cuerpos y pueblos por un modo aún más brutal y explotador de dominación capitalista (Boulwaire, 2016, 7-8). Si centramos la atención en el filme, los llamados soldados Media Vida, plagados de enfermedades resultantes de la contaminación ambiental y la mala nutrición, son la representación más obvia de los efectos del poder necropolítico y vendrían a encarnar a esos "muertos vivientes" que nombra Mbembe o esos "cyborgs" a los que alude Mary Daly, pues existen sólo para morir en el combate, son por tanto cuerpos corrompidos y explotados para mantener ese imperialismo extremo, de hecho su estética fantasmal acentúa esta idea de "muertos vivientes" (Fig. 6). Algo fundamental para el control del ejército de hombres Media Vida es la devoción religiosa impuesta por Immortan Joe, el cual es considerado por sus soldados como un dios que los guiará "eternos por los senderos del Valhalla" si dan la vida por él en la batalla. Esto último conecta con otra rama del ecofeminismo denominada Teología de la Liberación, la cual acusa al patriarcado de haber ejercido un dominio también espiritual (Castañer, 2015, 27). Una de sus teóricas referentes, Rosemary Radford Ruether (EE.UU., 1936), en su libro Gaia and God: An Ecofeminist Theology of Earth Healing, revisa los contenidos de las tradiciones griega y hebrea que recibe el cristianismo, no para proponer el culto a una Diosa, pero sí para criticar el deseo de inmortalidad y trascendencia de las grandes religiones monoteístas. Según la teóloga, el Padre Celestial promete la salvación si se desprecia el cuerpo y se aspira a una existencia liberada de toda relación con la naturaleza. Quien se somete a las religiones patriarcales, es recompensado con la fantasía de la superioridad sobre aquello que queda excluido o devaluado. Sostiene pues que el sexismo 


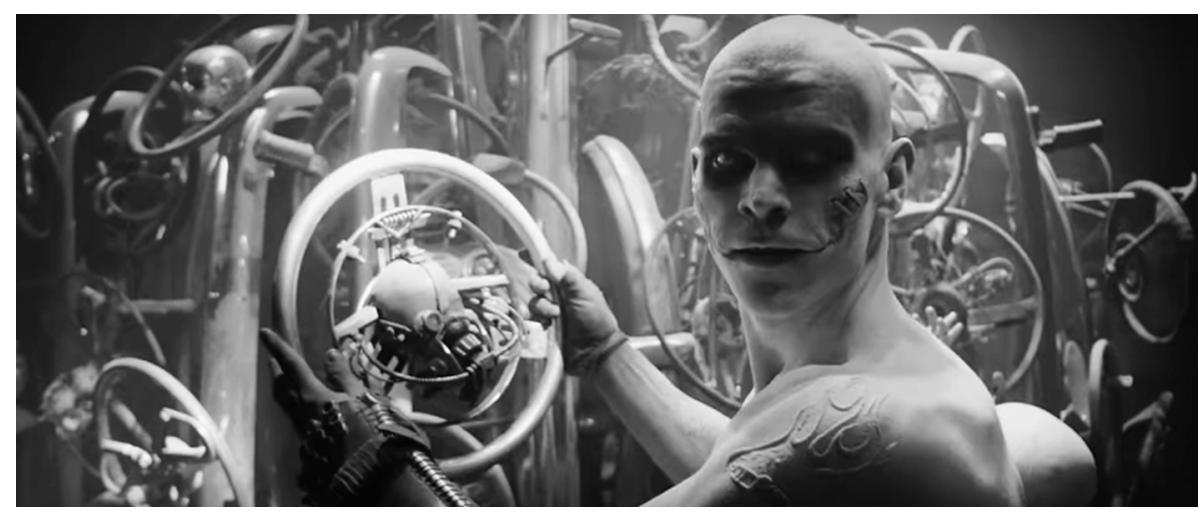

Fig. 6. Fotograma de Mad Max: Furia en la carretera (Mad Max: Fury Road, George Miller, 2015). Uno de los soldados Media Vida. Destaca su aspecto fantasmal. Captura de pantalla.

y el desprecio al mundo natural, son elementos constitutivos de estas grandes tradiciones religiosas (Puleo, 2011, 47-48), es justo esta base religiosa sobre la que se levanta todo el dominio que ejerce el villano en el filme, y contra lo que se rebelarán las mujeres logrando finalmente subvertir el sistema.

La filóloga Andrée Collard (Bélgica, 1926-1986), influenciada por las clases de ética feminista de Mary Daly, sostiene en su libro Rape of the Wild. Man's Violence against Animals and the Earth, que la conquista de la naturaleza que comenzó con la caza y la caída de la Diosa Madre sustituida por Dios Padre, tendría hoy su continuidad en la destrucción programada de los animales silvestres y de su hábitat, el envenenamiento masivo con productos químicos y la tortura sistemática en siniestros laboratorios de investigación científica. La violencia y la dominación que hoy se llama "progreso" son propias de una cultura de violadores y según ella "encontramos ejemplos de violación de lo salvaje cuando la naturaleza es nuevamente objetivada, investigada, usada y controlada" (Collard, 1988, 39). Afirma además que las mujeres conservan una capacidad de resistencia, un resto de lo salvaje, pues no han cortado sus lazos empáticos con los demás como lo exige la identidad viril. De hecho para Collard, la esperanza de evitar el colapso en la Tierra reside en las mujeres. En su opinión: "Las mujeres deben darse cuenta de que no podrán encontrar soluciones a la crisis ecológica mientras que la sociedad continúe fundando sus modelos de relación en sistemas de dominación" (Puleo, 2011, 50-51). En la película de Miller, se nos ofrece un desenlace que concuerda con esta idea, pues las mujeres se dan cuenta que han de 


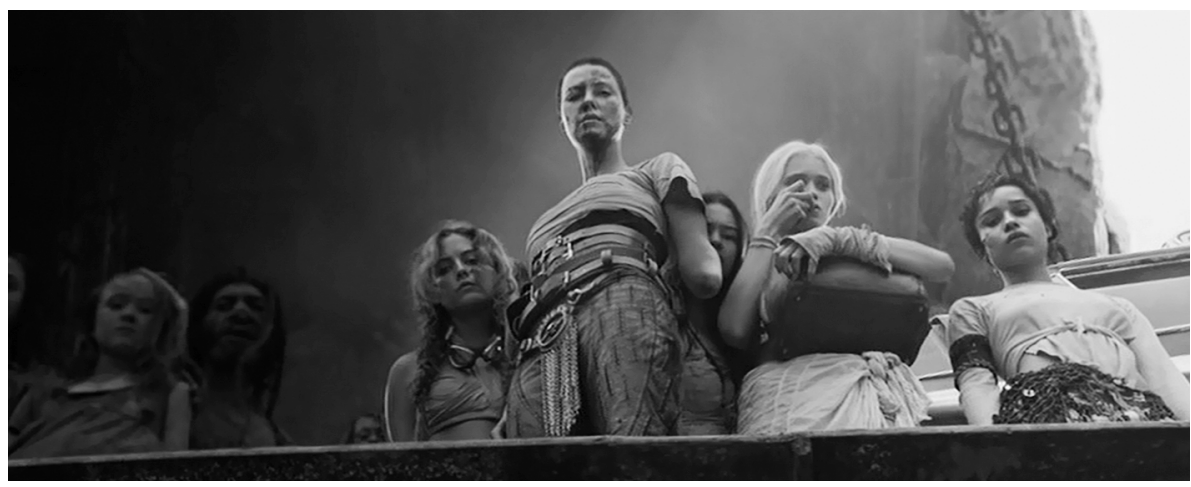

Fig. 7. Fotograma de Mad Max: Furia en la carretera (Mad Max: Fury Road, George Miller, 2015). Furiosa y las Esposas elevándose triunfantes en La Ciudadela. Captura de pantalla.

subvertir el orden establecido en La Ciudadela, y se muestra el matriarcado como única vía de supervivencia a través de un plano contrapicado en el que Furiosa junto con el resto de mujeres, se elevan sobre una plataforma hacia lo alto demostrando así el poder que ahora recae sobre ellas (Fig. 7).

Omar Feliciano, en un artículo para la revista online Animal Político, reflexiona acerca de la explotación hacia las mujeres que se recrea en el filme y lo compara con una realidad incómoda: la de que hoy en día miles de mujeres y niñas son esclavas de señores de la guerra, víctimas de la expansión de los fundamentalismos militantes en un contexto de crisis social generada por los efectos del cambio climático (Feliciano, 2015). Habla de Nigeria como el mejor ejemplo, pues muchos analistas han relacionado el papel del calentamiento global con la inestabilidad del país africano, ya que la crisis de agricultura de 2004 y 2005 favoreció flujos migratorios internos y la aparición de radicalismos como el de Boko Haram. Vale la pena mencionar que en relación a este hecho, la ONU pidió a Nigeria que permitiera el aborto a las niñas y mujeres rescatadas de Boko Haram, pero la demanda fue en vano (Comercio, 2015). De hecho en el filme, también se hace alusión en varias ocasiones al deseo de aborto de las Esposas de Immortan Joe: en una escena, Angarad, la Esposa favorita del villano, ejerce como escudo humano interponiéndose con su vientre embarazado entre Furiosa y el malvado caudillo para proteger a la Imperator. Se deduce por tanto, que aprecia más la vida de su compañera que la del hijo de su violador. En otro momento del filme, Dag, otra de las Esposas, habla con una de las Vuvalini refiriéndose al bebé que lleva en su interior: 
DAG: $\quad$ No salgas, pequeño Joe. Estás mejor dentro que fuera.

VuvaLINI: ¿Estás embarazada?

DAG: $\quad$ Caudillo hijo. Va a ser tan feo...

Vuvalins: Podría ser niña.

Se aprecia por tanto el desprecio que sienten las mujeres embarazadas de la película hacia sus futuros hijos, pues son fruto de una violación.

En resumen, la película denuncia el capitalismo y el patriarcado como culpables de la caída del mítico matriarcado originario y la miseria consecuente. Nos muestra pues, la conexión existente entre la masculinidad tóxica y patriarcal y la explotación capitalista, revelando cómo estas ideologías se complementan y funcionan para objetivar, mercantilizar, regular y explotar recursos y cuerpos, tales como los soldados Media Vida, las Esposas, las Madres de la Leche y las "bolsas de sangre" como Max.

Definitivamente Furia en la carretera no es una pieza maestra del feminismo o de la ecología, más bien es un ícono del cine de acción que ha conseguido subvertir los parámetros más evidentes de este tipo de cine, pero aún así, la intención es clara y el mensaje de George Miller contundente, y es realmente significativo que una película de estas características toque temas como los que acabamos de comentar.

Otro de los aspectos a tener en cuenta, es que, aunque Mad Max: Furia en la carretera recree un mundo y una sociedad ficticia, para algunos inimaginable, no dista mucho de la realidad o de las posibles consecuencias de nuestros actos, pues las equivalencias con nuestra existencia son fácilmente rastreables dentro del filme: guerras por combustibles, escasez de agua, explotación de la naturaleza, violación de los derechos de las mujeres, líderes que representan masculinidades tóxicas, refugiados en busca de lugares mejores, religiones como sistemas de control, etc.

De hecho, al vincularla con el problema medioambiental seguimos encontrando paralelismos con la realidad. La Vuvalini que guarda y protege con su vida una pequeña bolsa repleta de semillas como último vestigio de la humanidad, recuerda al Banco Mundial de Semillas de Svalbard (Noruega), un búnker situado a 1.300 kilómetros del Polo Norte construido para albergar semillas de todas partes del mundo, listas para ser cultivadas en caso de que tuviéramos que enfrentarnos a algún desastre. Esta especie de caja fuerte está pensada para soportar la actividad volcánica, terremotos e incluso la radiación de un posible cataclismo nuclear, según los medios. Su depósito contaba en 2015 con más de 830.804 variedades de semillas que representarían en torno a la mitad de los cultivos que se conocen en el mundo (Ayuso, 2015). Es interesante advertir que si se ha llegado a construir dicho sistema, es porque en parte, no se alberga de- 
masiada esperanza en los futuros actos del ser humano, y menos hoy en día con políticas tan conservadoras como las del actual presidente de Estados Unidos Donald Trump hacia el cambio climático. De hecho, existen una gran cantidad de estudios que advierten que nos estamos precipitando al abismo. Autoras como Noël Sturgeon, en su libro Environmentalism in Popular Culture: Gender, Race, Sexuality, and the Politics of the Natural, ofrece una vision muy crítica de la situación actual en el mundo y otros como Slavoj Žižek señalan que:

el sistema capitalista global está aproximándose a un apocalíptico punto cero. Sus "cuatro jinetes" están formados por la crisis ecológica, las consecuencias de la revolución biogenética, los desequilibrios dentro del propio sistema (los problemas de la propiedad intelectual; las luchas que se avecinan sobre las materias primas, los alimentos y el agua) y el explosivo crecimiento de las divisiones y exclusiones sociales (Žižek, 2012, 8).

Mad Max: Furia en la carretera es simplemente una interpretación de lo que podría acontecer en un futuro si las cosas no van por el buen camino, y el mensaje final que nos manda, es que, en las mujeres reside ese poder para cambiarlo todo. Hemos constatado por tanto, como en este filme se relaciona la problemática medioambiental con el abuso de poder por parte del sistema capitalista y patriarcal representado por una masculinidad tóxica y violenta en contraposición con la esencia pacífica, natural y espiritual de las mujeres.

\section{A MODO DE CONCLUSIÓN}

De lo que no cabe duda, es que el éxito financiero de Furia en la carretera y su gran popularidad entre las grandes audiencias así como dentro de la industria cinematográfica, parece indicar que realmente existe un espacio para películas feministas y ecológicas en Hollywood, donde la mujer sea tratada de la misma forma que el hombre, y donde se den una serie de paralelismos con una realidad social a la que no se hace frente fuera del plano fílmico como: el cambio climático, la explotación de los recursos naturales, el problema de los refugiados de guerra, el extremismo religioso y los derechos de la mujer.

Por lo tanto, llegamos a la conclusión de que también en las superproducciones hollywoodenses, se produce una crítica al sistema establecido y se propone un ejercicio de imaginación alternativa, en este caso protagonizado por mujeres empoderadas que luchan por legitimar los presupuestos ecologistas para salvar el mundo. Películas como ésta son realmente necesarias, pues se nos plantea cómo la ideología patriarcal está destruyendo el planeta y cómo una posición política como el ecofeminismo podría salvarlo. 


\section{BIBLIOGRAFÍA}

AYUSO, M. (2015): "La caja fuerte del fin del mundo que puede salvarnos de la destrucción", El Confidencial. Recurso en línea: https://www.elconfidencial.com/alm a-corazon-vida/2015-05-25/la-caja-fuerte-del-fin-del-mundo-que-puedesalvarnos-de-la-destruccion_852525/ (26-08-2017).

BALLARD, J.G. (2013): El mundo de cristal, Barcelona, RBA, 208 p.

BALLARD, J.G. (2002): El mundo sumergido, Barcelona, Minotauro, 224 p.

BALLARD, J.G. (2000): La sequía, Barcelona, Minotauro, 280 p.

BALLARD, J.G. (1966): El huracán cósmico, Barcelona, Edhasa, 238 p.

BOULWARE, T. (2016): “'Who killed the world?': Building a Feminist Utopia from the Ashes of Toxic Masculinity in Mad Max: Fury Road", Mise-en-scène. The Journal of Film \& Visual Narration, 1, 1-17.

BURGART GOUTAL, J. (2017): “Un nouveau printemps pour l'écoféminisme?", Multitudes, vol. 67, 2, 17-28.

CAHIERS DU CINEMA (2015): “Top Ten 2015 des Cahiers du cinéma”, Cahiers du Cinéma. Recurso en línea: https://www.cahiersducinema.com/produit/top-10-2015des-cahiers-du-cinema/ (27-08-2017).

CASTAÑER, X. (2015): Género y videocreación en el arte contemporáneo, Valencia, Tirant lo Blanch, $127 \mathrm{p}$.

CLAVIN, K. (2016): “Living, Again: Population and Paradox in Recent Cinema”, The Oxford Literary Review, 38, 47-65.

COLLARD, A. (1988): Rape of the Wild. Man's Violence against Animals and the Earth, United States, Indiana University Press, 187 p.

COMERCIO (2015): "Onu pide a Nigeria que deje abortar a víctimas de Boko Haram", El Comercio. Recurso en línea: http://elcomercio.pe/mundo/africa/onu-pidenigeria-deje-abortar-victimas-boko-haram -170632 (26-08-2017).

FELICIANO, O. (2015): "Mad Max: Furia Feminista", Animal Político. Recurso en línea: http://www.animalpolitico.com/blogueros-punto-gire/2015/08/24/mad-maxfuria-feminista/ (26-08-2017).

FIPRESCI (2015): “Mad Max: Fury Road Wins FIPRESCI Grand Prix”, Fipresci. Recurso en línea: http://www.fipre sci.org/news/grand-prix-2015 (27-08-2017).

HAWKING, S. (2017): "The future of the humanity", IV Festival científico y artístico Starmus, Norwegian University of Science and Technology, Trondheim, Noruega, 2017.

HAWKING, S. (2016): "This is the most dangerous time for our planet", The Guardian. Recurso en línea: https://www.theguardian.com/commentisfree/2016/dec/01/ stephen-hawking-dangerous-time-planet-inequality (11-04-2018).

LEYDA, J. (2016): “The Cultural Affordances of Cli-Fi”, en: The Dystopian Impulse of Contemporary Cli-Fi: Lessons and Questions from a Joint Workshop of the IASS and the JFKI (FU Berlín), Postdam, IASS, 11-17. 
PULEO, A. H. (2011): Ecofeminismo para otro mundo posible, Madrid, Cátedra Instituto de la mujer, $439 \mathrm{p}$.

SALAS, J. (2017): “2050: cómo evitar un futuro de Mad Max”, El País. Recurso en línea: https://elpais.com/elpais/2017/11/06/ciencia/1509924058_409061.html (1104-2018).

ŽIŽEK, S. (2012): Viviendo en el final de los tiempos, Madrid, Akal, 492 p. 